\title{
Defeating the Boss Level ... Exploring Inter-and-Multigenerational Gaming Experiences
}

\author{
Hannah R. Marston ${ }^{1}$ Ahmad Azadvar²,3 \\ Published online: 5 March 2020 \\ ๑) Springer Science+Business Media, LLC, part of Springer Nature 2020
}

Video games straddle both the twentieth and twenty-first centuries, the former been the place holder in the history of this entertainment medium. During the last couple of decades of the twentieth century, videogames emerged as a medium which is accessible to all citizens and spheres in society. Recent statistics published by the AARP organisation in the USA report that older adults (50+ years) play videogames on a daily basis, with older women in particular engaging with this medium. In contemporary society, according to the AARP's report, older gamers do not seek information or assistance from their children or grandchildren, but instead look to learn about new games via multiple channels, social media platforms and from various smartphone apps (Kakulla 2019).

The Entertainment Software Association (ESA) note in their 2019 analysis that $65 \%$ of American adults play videogames, with smartphones (60\%) being their most preferred device, followed by PCs (52\%) and specific game consoles (49\%). Overall, the casual game genre is their most preferred type of game, with $71 \%$ of respondents playing, followed by Action (53\%) and Shooter (47\%) game genres (ESA 2019). The ESA note that the average age of a gamer is 33 years who has been playing for 14 years; the average age is 34 years for a female gamer, and 32 years for a male gamer (ibid).

For different societal generations (e.g. Baby Boomers, Gen X, and Millennials) the ESA (2019) have presented various information surrounding gaming preferences (see Table 1), based on gender and digital devices. However, it is unclear how they have decided the age categories for the respective generations; and for Baby Boomers, they do not include older baby Boomers who in 2019 were 74 years and over.

Hannah R. Marston

Hannah.Marston@open.ac.uk

Ahmad Azadvar

Ahmad.Azadvar@massive.se

1 Health and Wellbeing Priority Research Area, School of Health, Wellbeing and Social Care, The Open University, Walton Drive, Milton Keynes, Buckinghamshire MK7 6AA, UK

2 Ubisoft, Massive Entertainment, Malmö, Sweden

3 Faculty of Technology and Society, Malmo University, Storgatan 15c, 21141 Malmö, Sweden 
Table 1 gaming demographics, preferences and digital devices (ESA 2019)

\begin{tabular}{|c|c|c|c|c|c|}
\hline Generation & Gender & Age range & Favourite Genre(s) & Favourite game(s) & Preferred device \\
\hline \multirow[t]{2}{*}{ Millennial } & Male & $18-34$ & $\begin{array}{l}\text { Action } \\
\text { Shooter } \\
\text { Sports }\end{array}$ & $\begin{array}{l}\text { God of War } \\
\text { Madden NFL } \\
\text { Fortnite }\end{array}$ & Game console \\
\hline & Female & & $\begin{array}{l}\text { Casual } \\
\text { Action }\end{array}$ & $\begin{array}{l}\text { Candy Crush } \\
\text { Assassin's Creed } \\
\text { Tomb Raider }\end{array}$ & Smartphone \\
\hline \multirow[t]{2}{*}{ Generation X } & Male & $35-54$ & $\begin{array}{l}\text { Sports } \\
\text { Racing } \\
\text { Shooters }\end{array}$ & $\begin{array}{l}\text { Forza } \\
\text { NBA } 2 \mathrm{~K} \\
\text { Call of Duty }\end{array}$ & Smartphone \\
\hline & Female & & $\begin{array}{l}\text { Casual Games, includ- } \\
\text { ing Puzzle and Classic } \\
\text { Arcades }\end{array}$ & $\begin{array}{l}\text { Tetris } \\
\text { Pac-Man }\end{array}$ & Smartphone \\
\hline \multirow[t]{2}{*}{ Baby Boomers } & Male & $55-64$ & $\begin{array}{l}\text { Card } \\
\text { Puzzle }\end{array}$ & $\begin{array}{l}\text { Solitaire } \\
\text { Scrabble }\end{array}$ & $\mathrm{PC}$ \\
\hline & Female & & Virtual Board Games & $\begin{array}{l}\text { Mahjong } \\
\text { Monopoly }\end{array}$ & Smartphone \\
\hline
\end{tabular}

Furthermore, as far as some members of Generation $\mathrm{X}$ might opine, it is probable that the ESA 2019 report is including/merging Millennials into the lower-end of Generation X.

This iGAME special issue is timely, given the rise of interest in the use of technology to facilitate a myriad of societal challenges and enablers, ranging from health-related concerns to ageing populations.

iGAME opens with a review by Marston and Duro, who explore published, empirical research reporting on participants categorised as members of Generation X (Vogels 2018; Nielsen 2014). To date, there has been substantial interest and research in the realm of videogames by children and by older adults, and on their practical applications in terms of addressing health and wellbeing, mental health, obesity, game playing preferences, design, motivation and experiences. However, as we enter our third decade of the twenty-first century, academe and industry have been slow to diversify their scholarly activities and to broaden their interest regarding this medium and how videogames impact on the lives of Generation X within society. It could be asked why Generation $\mathrm{X}$ should be given special attention, particularly when Millennials now play a prominent role in society; however, given the national and international interests of governments relating to longevity (social) loneliness and active and healthy ageing (Marston and van Hoof 2019), exploring and investigating the issues, needs and requirements of future ageing populations is crucial, particularly when respective cohorts reach old age.

There is a breadth of work surrounding technology and game studies research associated with older adults, which has and continues to push the boundaries in a bid to move international debates forward (Brown 2019; Brown and De Schutter 2016; Osmanovic and Pecchioni 2016; Marston and Graner-Ray 2016; De Schutter and Brown 2015; Charness 2014; Belchior et al. 2013; Allaire et al. 2013; Marston 2013a, b; Brown 2012; McLaughlin et al. 2012; Mitzner et al. 2010; De 
Schutter 2010; Vanden Abeele and De Schutter 2010; Basak et al. 2008; Ijsselsteijn et al. 2007; Goldstein et al. 1997; Whitcomb 1990). This scholarly work has proved critical in offering baseline data and insights, which have in turn offered scholars the opportunity to build upon and explore other segments and cohorts in society (Marston 2019; Brown and Marston 2018; Brown 2016). Marston and Duro present findings from a scoping review of scholarly work focusing on participants who are now categorised as members of Generation X. Their research spans the years 1970-2000 across various databases. Their results are sourced from 21 papers, from which five primary and seven secondary themes were ascertained in the analysis.

Our second paper by Havukainen and colleagues take a case study approach in a bid to explore and understand the design of a digital game by recruiting both children and older adults through a co-production/design approach. Havukainen and colleagues propose a co-design process model that takes into consideration an intergenerational perspective when collaboratively and creatively working on videogame design(s). In this particular instance, game designers used concepts associated with childhood memories of the older participants, while exploring innovative game content based on new words and concepts by young people (12-13 years old). From this co-production process several game elements were identified which were deemed essential for integration into the game designs.

Our third paper in this issue tackles the sensitive but important issues of abuse, mistreatment and accessibility, intersecting across the fields of Game Studies and Gerontology. Through a fictional concept, Lafontaine and colleagues co-create and design the notion of an escape room for older adults, via the design of puzzle games. A qualitative multi-methods approach was instilled using interviews and ethnographic notes, which were used to address and transfer discussion and conversation surrounding this sensitive topic into videogame designs, reaching both younger adults and targeting older adults. Lafontaine and colleagues aim to address the issues of such a sensitive topic by illustrating how conversations can be implemented into a digital medium, in a bid to create an innate intergenerational relationship and design process while employing a videogame framework. This contribution by Lafontaine and colleagues highlights and brings to the forefront the need for a valuable discussion on the value of intergenerational facilitation within this arena.

Our fourth paper by Julie Hicks Patrick and colleagues presents empirical data based on PokemonGo. This study examines the wellbeing of players, and players' motivations for engaging with a particular location-based game. A total of 130 participants who were PokemonGo players and aged between 19 and 76 years were recruited. The survey results identify that $73 \%$ of the participants chose to play PokemonGo alone, while around 34\% reported playing because PokemonGo offers them the chance to form new social connections.

Our penultimate paper is by Khalili-Mahani and colleagues, who present perspectives from a series of qualitative data surrounding three serious games. Participants aged between 65 and 90 years were recruited in conjunction with young research students. Older participants with little or no videogame experience or knowledge were also recruited to take part in the study. Qualitative data (comprising over $100 \mathrm{~h}$ of conversations with participants) exploring the cognitive benefits of playing videogames were collected. Additional phases of data collection were conducted through 
community classes, enabling the research team to share the various facets of gaming to the participants. This in turn facilitated the members of the community classes to share their stories, ranging from gaming experiences to cultural differences and significances. This paper presents multiple findings on the novel gaming experiences of the participants. Khalili-Mahani and colleagues report that the primary motivation for playing serious games is for fun, and note that the complexity of differential personal preferences of the older participants guaranteeing a direct conceptualisation of videogame preferences is more difficult than for a homogenous group.

Our final contribution is by Azardvar and Dalqvist, who present findings from an industry perspective. Their paper is based on an empirical study conducted by Ubisoft entertainment Sweden, which involves 7000 players of Tom Clancy's 'The Division'. Azardva and Dalqvist analyse player behavioural data, as extracted from the game's tracking engine, and cross-reference various age groups in their exploration of the relationships between motivation, behaviour and habitual characteristics. Their findings focus on demographic data, the affinity for playing different types of videogames, and gamers' psychological needs satisfaction. In their comparison across the different generations, they identify that the older players tended to feel more agentic and present in the narrative, and experienced a sense of feeling towards the non-playable characters (NPCs), while they also felt less competent during their game playing sessions.

The goal of the iGAME special issue is to illustrate and present existing data, thoughts, debates and insights into contemporary and future game studies and interdisciplinary research in a bid to extend and broaden the existing arena of intergenerational gaming and game studies. This collection of papers has delivered an array of international scholarly and industry perspectives, which intersects across several fields including: gerontechnology, social sciences, design and development, and gerontology.

The iGAME special issue impacts on academe as a means of moving research forward as well as industry learning, building and implementing scholarly activity into their own in-house research units. The iGAME special issue illustrates how intergenerational gaming is integral to society in both the developed Western world and also in low and middle-income countries (LMICs), while demonstrating the need for greater emphasis by both the academe and industry spheres to move intergenerational research forward. This in turn is critical for all stages of the design and development lifecycle, and taking a co-creation and production approach is key towards ensuring all voices and narratives are recorded.

Moving forward within a more digitalized societal ecosystem, and understanding the needs and concerns, as well as managing expectations of, younger cohorts such as Generation X, Millennials and Generation Z in conjunction with existing older cohorts is necessary if we are to be prepared for attending to the needs of future ageing populations. By this, we mean individuals categorised as Generation $\mathrm{X}$ or Millennials, who have very different experiences to existing older adults. While academe is primarily focusing on older cohorts in conjunction with contemporary government agendas, future aging populations will have different attitudes and requirements in terms of digital entertainment. 


\section{References}

Allaire, J. C., Collins McLaughlin, A., Trujillo, A., Whitlock, L. A., LaPorte, L., \& Gandy, M. (2013). Successful aging through digital games: Socioemotional differences between older adult gamers and Non-gamers. Computers in Human Behavior, 29(4), 1302-1306. https://doi.org/10.1016/j. chb.2013.01.014.

Basak, C., Boot, W. R., Voss, M. W., \& Kramer, A. F. (2008). Can training in a real-time strategy video game attenuate cognitive decline in older adults? Psychology and Aging, 23(4), 765-777. https://doi.org/10.1037/a0013494.

Belchior, P., Marsiske, M., Sisco, S. M., Yam, A., Bavelier, D., Ball, K., et al. (2013). Video game training to improve selective visual attention in older adults. Computers in Human Behavior, 29(4), 1318-1324. https://doi.org/10.1016/j.chb.2013.01.034.

Brown, J. A. (2012). Let's play: Understanding the role and meaning of digital games in the lives of older adults. In Proceedings of the international conference on the foundations of digital games (FDG'12). Association for Computing Machinery, New York, NY, USA, pp. 273-275. https:// doi.org/10.1145/2282338.2282396.

Brown, J. A. (2016). Exploring the next generation of older gamers: Middle-aged gamers. In J. Zhou \& G. Salvendy (Eds.), Human aspects of IT for the aged population. Healthy and active aging. ITAP 2016. Lecture notes in computer science (Vol. 9755). Cham: Springer.

Brown, J. A. (2019). An exploration of virtual reality use and application among older adult populations. Gerontology and Geriatric Medicine. https://doi.org/10.1177/2333721419885287.

Brown, J. A., \& De Schutter, B. (2016). Game design for older adults: Lessons from a life course perspective. International Journal of Gaming and Computer-Mediated Simulations (IJGCMS), 8(1), 1-12. https://doi.org/10.4018/IJGCMS.2016010101.

Brown, J. A., \& Marston, H. R. (2018). Gen X and digital games: Looking back to look forward. In J. Zhou \& G. Salvendy (Eds.), Human aspects of IT for the aged population. Applications in health, assistance, and entertainment. ITAP 2018. Lecture notes in computer science (Vol. 10927). Cham: Springer. https://doi.org/10.1007/978-3-319-92037-5_34.

Charness, N. (2014). Utilizing technology to improve older adult health. Occupational Therapy in Health Care, 28, 21-30. https://doi.org/10.3109/07380577.2013.865859.

De Schutter, B. (2010). Never too old to play: The appeal of digital games to an older audience. Games and Culture: A Journal of Interactive Media, 6(2), 155-170.

De Schutter, B., \& Brown, J. A. (2015). Digital games as a source of enjoyment in later life. Games and Culture: A Journal of Interactive Media. https://doi.org/10.1177/1555412015594273.

Entertainment Software Association. (2019). Essential facts about the computer and video game industry. Retrieved February 20, 2020 from https://www.theesa.com/esa-research/2019-essen tial-facts-about-the-computer-and-video-game-industry/.

Goldstein, J., Cajko, L., Oosterbroek, M., Michielsen, M., Van Houten, O., \& Femke, S. (1997). Video games and the elderly. Social Behavior and Personality: An International Journal, 25(4), 345-352. https://doi.org/10.2224/sbp.1997.25.4.345.

Ijsselsteijn, W., Nap, H. H., de Kort, Y., \& Poels, K. (2007). Digital game design for elderly users. In Proceedings of the 2007 conference on future play (Future Play'07). Association for Computing Machinery, New York, NY, USA, pp. 17-22. https://doi.org/10.1145/1328202.1328206.

Kakulla, B. (2019). Gaming attitudes and habits of adults age S 50-plus. AARP. https://doi. org/10.26419/res.00328.001.

Marston, H. R. (2013a). Design recommendations for digital game design within an aging society. Educational Gerontology, 39(2), 103-118. https://doi.org/10.1080/03601277.2012.689936.

Marston, H. R. (2013b). Digital gaming perspectives of older adults: Content versus interaction. Educational Gerontology, 39(3), 14-208. https://doi.org/10.1080/03601277.2012.70081.

Marston, H., \& Graner-Ray, S. (2016). Older Women on the Game: Understanding Digital Game Perspectives from an Ageing Cohort. Ageing and Technology: Perspectives from the Social Sciences (pp. 67-92). Bielefeld: transcript Verlag. https://doi.org/10.14361/9783839429570-004.

Marston, H. R. (2019). Millennials and ICT-Findings from the technology 4 young adults (T4YA) project: An exploratory study. Societies, 9, 80. https://doi.org/10.3390/soc9040080.

Marston, H. R., \& van Hoof, J. (2019). Who Doesn't think about technology when designing urban environments for older people? A case study approach to a proposed extension of the WHO'S 
age-friendly cities model. International Journal of Environmental Research and Public Health, 16(19), 3525. https://doi.org/10.3390/ijerph16193525.

McLaughlin, A., Gandy, M., Allaire, J., \& Whitlock, L. (2012). Putting fun into video games for older adults. Ergonomics in Design, 20(2), 13-22. https://doi.org/10.1177/1064804611435654.

Mitzner, T. L., Boron, J. B., Fausset, C. B., Adams, A. E., Charness, N. C., Dijkstra, S. J., et al. (2010). Older adults talk technology: Technology usage and attitudes. Computers in Human Behavior. https ://doi.org/10.1016/j.chb.2010.06.020.

Nielsen. (2014). Millennials-breaking the myths. Nielsen Company: New York, NY; Dieman, The Netherlands.

Osmanovic, S., \& Pecchioni, L. (2016). Beyond entertainment: Motivations and outcomes of video game playing by older adults and their younger family members. Games and Culture, 11(1-2), 130-149. https://doi.org/10.1177/1555412015602819.

Vanden Abeele, V., \& De Schutter, B. (2010). Designing intergenerational play via enactive interaction, competition and acceleration. Personal and Ubiquitous Computing, 14(5), 425-433.

Vogels, E. A. (2018). Millennials stand out for their technology use, but older generations also embrace digital life. Pew Research Center: Washington, DC, USA; Retrieved November 21, 2019 from https ://www.pewresearch.org/fact-tank/2019/09/09/us-generations-technology-use/.

Whitcomb, G. R. (1990). Computer games for the elderly. In Proceedings of the conference on Computers and the quality of life (CQL'90). Association for Computing Machinery, New York, NY, pp. 112-115. https://doi.org/10.1145/97344.97401. 